\title{
Sensorless Field-Oriented Control for Double-Inverter-Fed Wound-Rotor Induction Motor Drive
}

\author{
Gautam Poddar and V. T. Ranganathan, Senior Member, IEEE
}

\begin{abstract}
A novel control technique for sensorless vector control operation of a double-inverter-fed wound-rotor induction motor is presented. Two current controllers control the stator-side currents based on a vector control algorithm. Another $V / f$-type flux and frequency controller controls the rotor-side frequency directly. A novel frequency command profile for the rotor-side controller is suggested to make this sensorless drive operation reliable and reduce dependence on motor parameters at any rotor speed. A complete inverter power flow analysis is presented to show that the drive can deliver full torque from 0- to 2-p.u. speed for either direction of rotation. Thus, double the rated power can be extracted from the induction motor without overloading it. The proposed algorithm allows the drive to start on-the-fly without any rotor transducer. Results from a prototype 50-hp drive are presented.
\end{abstract}

Index Terms-Double-inverter-fed drive, sensorless control, wound-rotor induction motor.

\section{NOMENCLATURE}

WRIM Wound-rotor induction motor.

$L_{s}, L_{r} \quad$ Stator and rotor self-inductances.

$L_{0} \quad$ Mutual inductance.

$\sigma_{s}, \sigma_{r} \quad$ Stator and rotor leakage factors.

$\sigma \quad$ Total leakage factor.

$R_{s}, R_{r} \quad$ Stator and rotor resistances.

$\bar{i}_{s} \quad$ Stator current vector in stationary reference frame.

$i_{s d} \quad d$-axis stator current.

$i_{s q} \quad q$-axis stator current or torque current.

$\bar{i}_{r}$

$i_{r d}$

$i_{r q}$

$\bar{V}_{s} q$

$\bar{V}_{r}$

Rotor current vector in rotor reference frame. $d$-axis rotor current. $q$-axis rotor current or torque current. Stator voltage vector in stationary reference frame. Rotor voltage vector in rotor reference frame. Stator flux vector in stationary reference frame. Rotor flux vector in rotor reference frame. Rotor flux vector in stationary reference frame. Stator supply frequency with respect to stationary frame.

$\omega_{m r} \quad$ Rotor flux speed with respect to stationary frame.

$\omega_{r} \quad$ Rotor supply frequency with respect to rotor frame.

$\omega_{e} \quad$ Actual rotor speed (electrical $\mathrm{rad} / \mathrm{sec}$ )

Manuscript received October 7, 2002; revised June 11, 2004. Abstract published on the Internet July 15, 2004. This work was supported by the Ministry of Information Technology, Government of India.

G. Poddar is with the Department of Electrical Engineering, Indian Institute of Technology, Kharagpur, 721 302, India (e-mail: gpoddar@ee.iitkgp.ernet.in).

V. T. Ranganathan is with the Electrical Engineering Department, Indian Institute of Science, Bangalore 560 012, India (e-mail: vtran@ee.iisc.ernet.in).

Digital Object Identifier 10.1109/TIE.2004.834970 $\omega_{e}^{\prime} \quad$ Estimated rotor speed.

$\varepsilon \quad$ Angle between rotor and stator axis.

$\rho_{m r} \quad$ Rotor flux angle with respect to stator axis.

$\rho_{m s} \quad$ Stator flux angle with respect to stator axis.

\section{INTRODUCTION}

$\mathbf{R}$ ECENTLY, it has been shown that a grid-connected wound-rotor induction motor with current injection on the rotor side can be operated in supersynchronous mode to produce up to two times the rated nominal power [1]. However, such a configuration does not have the capability of smooth speed reversal. A more versatile configuration is one wherein the stator and the rotor of the wound-rotor induction motor can be fed from variable-frequency inverters. In [2] it has been shown that this configuration has the capability of operating in all four quadrants of the speed-torque plane. The control scheme of [2] has two separate torque-current controllers for both stator- and rotor-side inverters. However, as shown in the following, the stator torque current and the rotor torque current are proportional to each other. Thus, separate torque-current controllers for both the stator and the rotor can lead to instability problems. This scheme also shows an abnormal rise of torque current during speed reversal and is sensitive to motor parameters.

The problem of achieving high dynamic performance in ac motor drives without the need for a shaft position/speed sensor has been studied extensively in the literature. The advantages of speed-sensorless operation of the drives are lower cost, reduced size of the drive machine, elimination of the sensor cable, and increased reliability. Generally, all the sensorless control methods for the ac machines have limitations near zero rotor speed (more accurately, near zero supply frequency) [3]-[8]. Thus, it is important to study this sensorless double-inverter-fed wound-rotor drive to check whether this topology can resolve this issue for a sensorless ac drive without sacrificing the dynamic and steady-state performance.

In this paper, a novel sensorless vector control algorithm is proposed to control the double-inverter-fed wound-rotor induction motor using a rotor-flux-oriented model of the motor. Two independent current controllers control the stator currents. One current controller controls the stator-side torque current and the other current controller controls the magnetizing current shared by the stator-side inverter. The rotor-side inverter has a simple $V / f$-type scalar control. The rotor supply frequency command of this $V / f$-type control is based on estimated rotor speed. The 


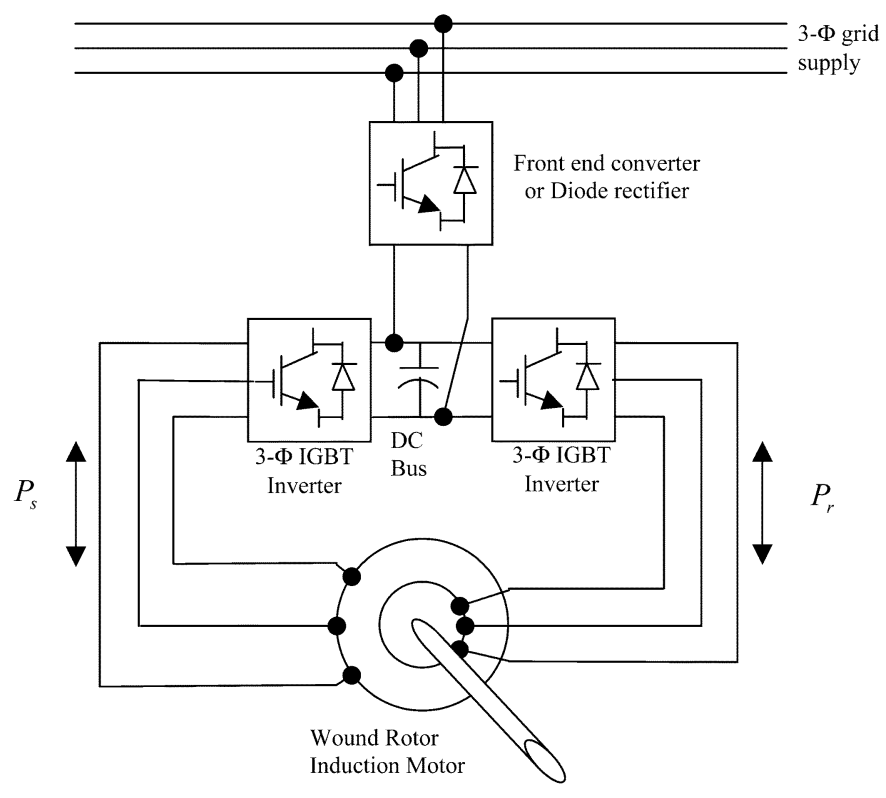

Fig. 1. Double-inverter-fed wound-rotor induction motor drive.

ratio of $V / f$ determines the total magnetizing current of the machine. The proposed algorithm is less dependent on motor parameters and eliminates the possibility of instability. This makes the drive more reliable. This proposed algorithm runs up to double the rated speed and, thus, enables generation of twice the rated power from the motor without overloading the motor.

Generally, sensorless operation is unreliable near zero rotor speed [3]-[8] because of the low frequency of operation. In the proposed scheme, a novel frequency generator is derived, which avoids low-frequency operation on both sides (rotor as well as stator) at all speeds. This ensures stable and reliable operation near zero speed including stall operation. Rotor speed/position transducers can, therefore, be removed completely.

\section{FundAMENTALS OF BASIC CONFIGURATION}

The configuration of the double-inverter-fed induction motor drive is shown in Fig. 1. A three-phase inverter rated 1 p.u. feeds power to the wound-rotor induction motor through its stator terminals. Another three-phase 1-p.u. inverter feeds power to the same motor through its rotor terminals. Now, the motor analysis is given to identify the control method suitable for this configuration. In this paper, the rotor-flux-oriented model of the motor is only considered for the vector control operation. However, from the electrical equivalence of the stator and the rotor of the wound-rotor motor, it can be easily shown that the stator-flux orientation also gives a similar model of the motor.

\section{A. Motor Model With Rotor-Flux Orientation}

The stator and the rotor voltage equations are furnished below in stator and rotor coordinates, respectively,

$$
\begin{aligned}
& \bar{V}_{s}=R_{s} \bar{i}_{s}+L_{s} \frac{d \bar{i}_{s}}{d t}+L_{0} \frac{d}{d t}\left[\bar{i}_{r}-e^{j \varepsilon}\right] \\
& \bar{V}_{r}=R_{r} \bar{i}_{r}+L_{r} \frac{d \bar{i}_{r}}{d t}+L_{0} \frac{d}{d t}\left[\bar{i}_{s} e^{-j \varepsilon}\right] .
\end{aligned}
$$

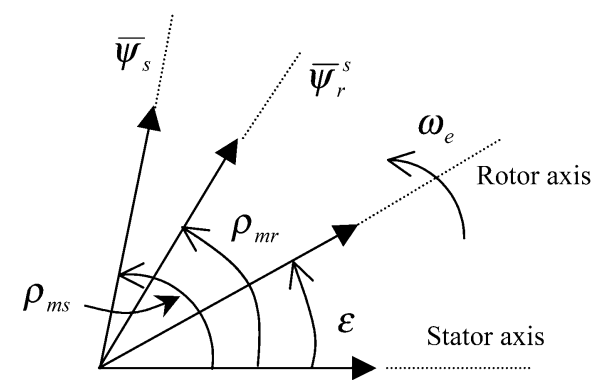

Fig. 2. Angular position of rotor and stator flux vector.

The rotor flux in the stator reference frame $\psi_{r}^{s}$ can be written as

$$
\bar{\psi}_{r}^{s}=\bar{\psi}_{r} e^{j \varepsilon}=L_{0}\left\{\left(1+\sigma_{r}\right) \bar{i}_{r} e^{j \varepsilon}+\bar{i}_{s}\right\}
$$

Fig. 2 shows the angular position of this rotor-flux vector. Transforming to a coordinate system aligned to the rotor flux and separating into real and imaginary parts

$$
\begin{aligned}
& \psi_{r}=L_{0}\left\{i_{s d}+\left(1+\sigma_{r}\right) i_{r d}\right\} \\
& i_{s q}=-\left(1+\sigma_{r}\right) i_{r q} .
\end{aligned}
$$

The $d$-axis and the $q$-axis voltage equations are also stated here using (1)

$$
\begin{aligned}
& V_{r d}=R_{r} i_{r d}+\frac{d \psi_{r}}{d t} \\
& V_{r q}=R_{r} i_{r q}+\psi_{r} \omega_{r} \\
& V_{s d}=R_{s} i_{s d}+\sigma L_{s} \frac{d i_{s d}}{d t}-\underline{\sigma L_{s} \omega_{m r} i_{s q}}+\frac{1}{\frac{1+\sigma_{r}}{1+} \frac{d \psi_{r}}{d t}} \\
& V_{s q}=R_{s} i_{s q}+\sigma L_{s} \frac{d i_{s q}}{d t}+\underline{\sigma L_{s} \omega_{m r} i_{s d}}+\underline{\omega_{m r} \frac{\psi_{r}}{1+\sigma_{r}}} .
\end{aligned}
$$

Finally, the torque of the motor is calculated as

$$
m_{d}=\frac{2}{3}\left(\frac{P}{2}\right) \frac{\psi_{r}}{1+\sigma_{r}} i_{s q}
$$

\section{B. Sensorless Estimation of Rotor Flux Vector}

In our sensorless rotor-flux orientation, the rotor-flux position $\rho_{m r}$ (Fig. 2) is to be estimated without the information of rotor position $\varepsilon$. Thus, an indirect method of estimating $\rho_{m r}$ is employed here as given by

$$
\begin{aligned}
& \bar{\psi}_{s}=L_{0}\left\{\left(1+\sigma_{s}\right) \bar{i}_{s}+\bar{i}_{r} e^{j \varepsilon}\right\} \\
& \bar{\psi}_{r}^{s}=\bar{\psi}_{r} e^{j \varepsilon}=L_{0}\left\{\left(1+\sigma_{r}\right) \bar{i}_{r} e^{j \varepsilon}+\bar{i}_{s}\right\}
\end{aligned}
$$

where the stator flux $\left(\bar{\psi}_{s}\right)$ and the rotor flux $\left(\bar{\psi}_{r}^{s}\right)$ are given here for the stationary reference frame.

Equating $\bar{i}_{r} e^{j \varepsilon}$ from the above equations, the relation between the stator and the rotor-flux vectors can be derived as

$$
\bar{\psi}_{r}^{s}=\frac{L_{r}}{L_{0}}\left\{\bar{\psi}_{s}-\sigma L_{s} \bar{i}_{s}\right\}
$$




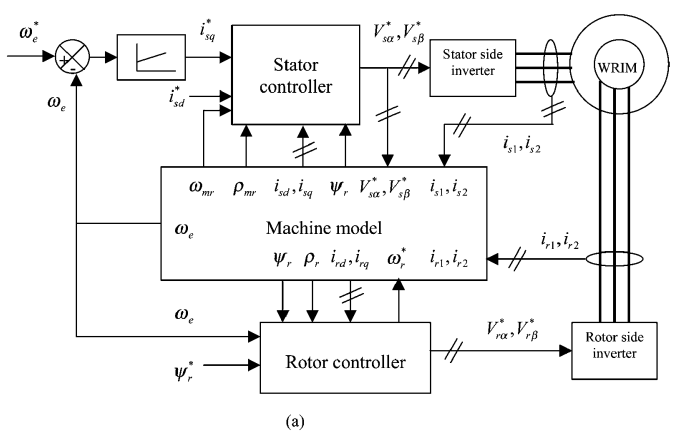

(a)

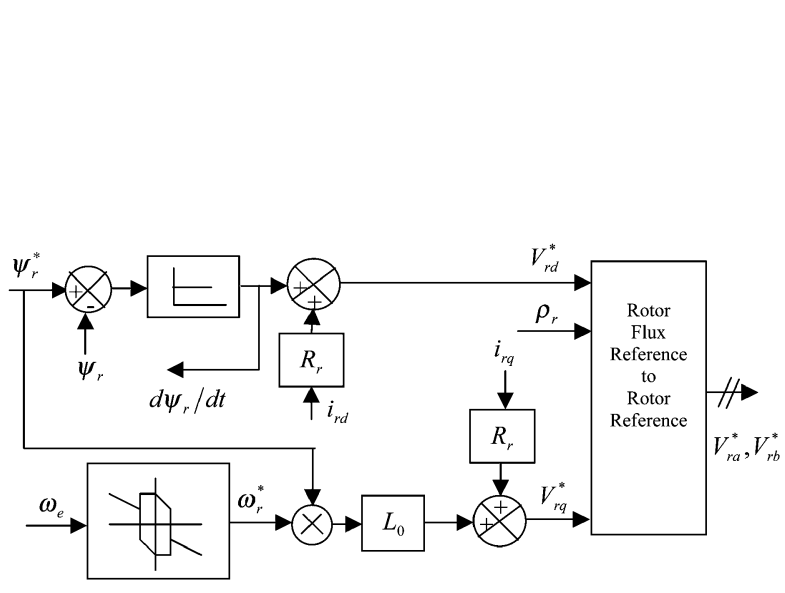

(c)

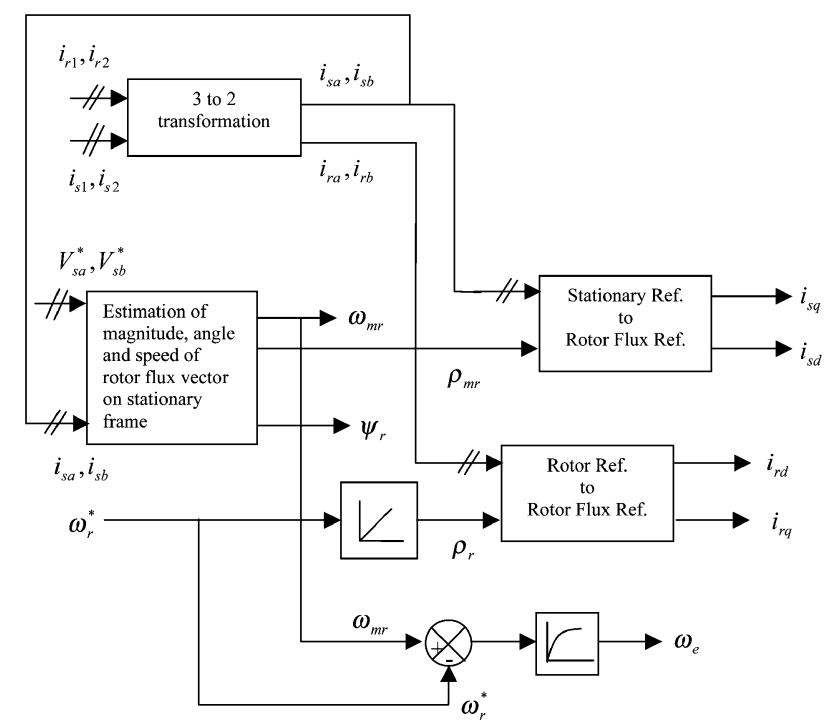

(b)

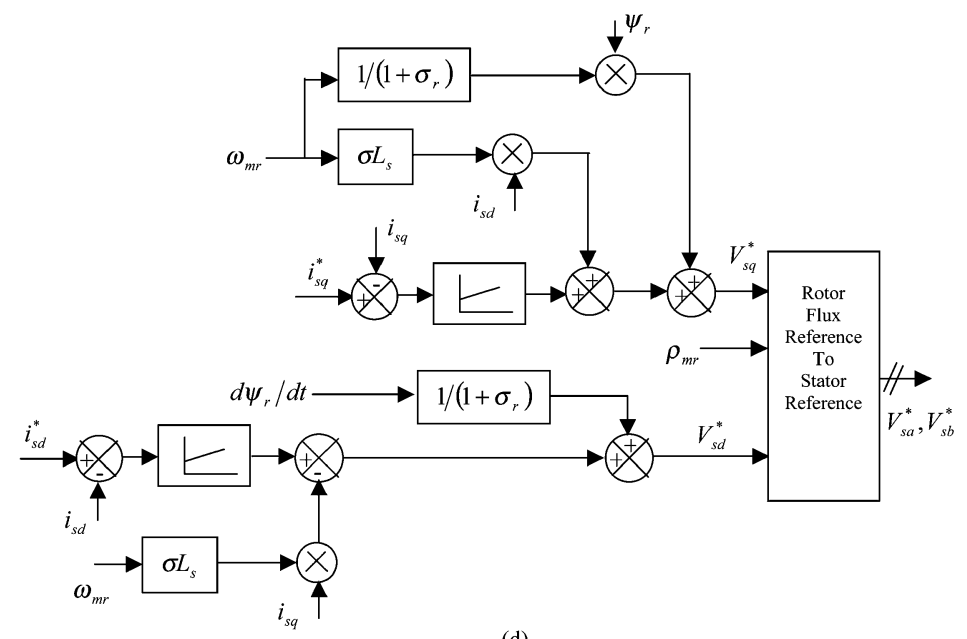

(d)

Fig. 3. Controller block diagram of sensorless vector control drive. (a) Overall controller. (b) Machine model. (c) Rotor-side controller. (d) Stator-side controller.

where $\sigma=1-\left(1 /\left(1+\sigma_{s}\right)\left(1+\sigma_{r}\right)\right)$ is the total leakage factor of the machine. Now, the stator-flux vector $\bar{\psi}_{s}$ is estimated from the stator supply voltage $\bar{V}_{s}$ as

$$
\bar{\psi}_{s}=\int\left(\bar{V}_{s}-R_{s} \bar{i}_{s}\right) d t
$$

Substituting (9) in (8), the estimated rotor flux vector can be written as

$$
\bar{\psi}_{r}^{s}=\frac{L_{r}}{L_{0}}\left[\int\left(\bar{V}_{s}-R_{s} \bar{i}_{s}\right) d t-\sigma L_{s} \bar{i}_{s}\right] .
$$

However, if the stator resistance $R_{s}$ and the total leakage of the motor $\sigma L_{s}$ are not measured accurately, the estimated stator flux $\bar{\psi}_{s}$ may get saturated due to the effect of de drift of pure integration. Practically, the deadband of a pulse widthmodulated (PWM) inverter and inaccurate estimation of dc-bus voltage can also cause similar difficulties. This problem is tackled by replacing the pure integration of (9) with a low-pass filter whose cutoff frequency is very low compared to the minimum stator supply frequency [6].
Now, the rotor flux magnitude $\left(\psi_{r}\right)$ and the unit vectors $\left(\cos \rho_{m r}, \sin \rho_{m r}\right)$ in rotor field coordinates can be derived as

$$
\begin{aligned}
\bar{\psi}_{r}^{s} & =\psi_{r \alpha}^{s}+j \psi_{r \beta}^{s} \\
\psi_{r} & =\left|\bar{\psi}_{r}^{s}\right|=\sqrt{\psi_{r \alpha}^{s^{2}}+\psi_{r \beta}^{s^{2}}} \\
\cos \rho_{m r} & =\frac{\psi_{r \alpha}^{s}}{\left|\bar{\psi}_{r}^{s}\right|} \\
\sin \rho_{m r} & =\frac{\psi_{r \beta}^{s}}{\left|\bar{\psi}_{r}^{s}\right|} .
\end{aligned}
$$

The angular velocity of the rotor flux $\left(\omega_{m r}\right)$ can be estimated using the following equation:

$$
\omega_{m r}=\cos \rho_{m r} \cdot \frac{d \sin \rho_{m r}}{d t}-\sin \rho_{m r} \cdot \frac{d \cos \rho_{m r}}{d t} .
$$

The differential terms in the above equation contribute to some noise, which can be eliminated by employing a first-order lowpass filter. Finally, the rotor speed $\omega_{e}$ is obtained as follows:

$$
\omega_{e}=\omega_{m r}-\omega_{r} .
$$




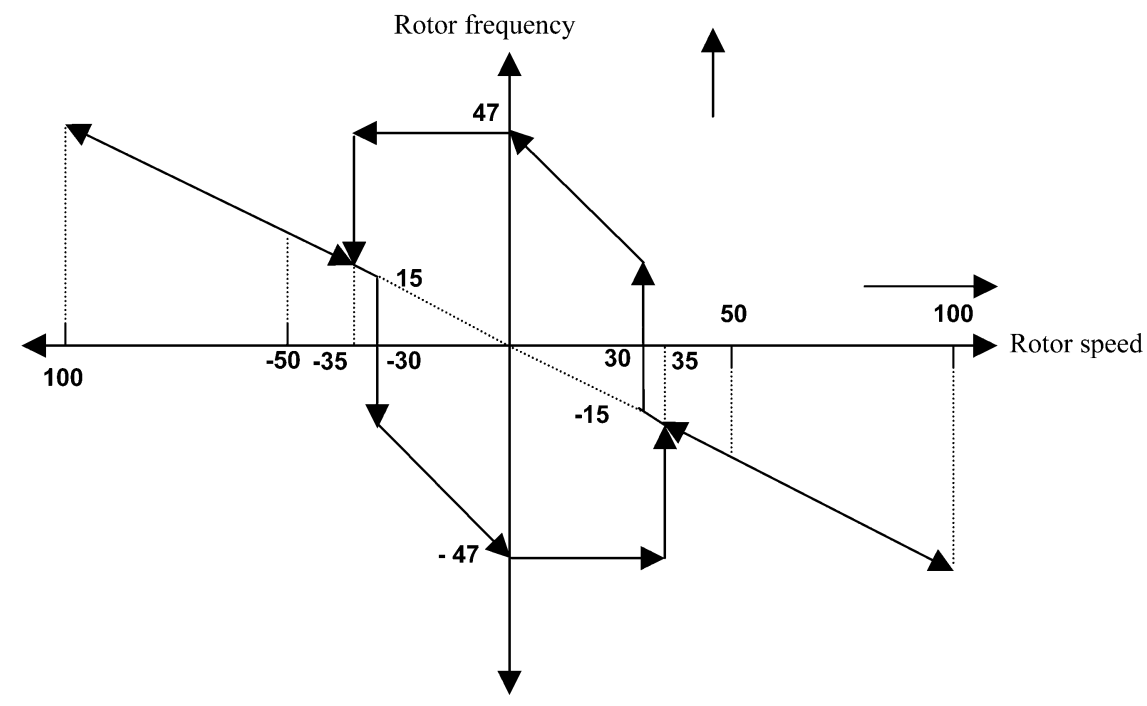

Fig. 4. Rotor frequency command versus rotor speed.

\section{Proposed CONTROL METHOD}

The block diagram of the proposed controller is shown in Fig. 3. Fig. 3(a) shows the overall control block diagram of the drive with various sub-blocks. The block diagram of each subblock is presented in Fig. 3(b)-(d). These blocks are explained in Sections III-A-D.

\section{A. Stator-Side Controller}

The $d$-axis and the $q$-axis voltage equations represent the first-order dynamics of the stator currents $\left(i_{s d}, i_{s q}\right)$ if the underlined terms are removed from (5) to decouple the $d$-axis and $q$-axis quantities. Thus, simple proportional-integral (PI) controllers can efficiently control the currents $\left(i_{s d}, i_{s q}\right)$ as shown in Fig. 3. The desired responses of $i_{s q}$ and $i_{s d}$ can be achieved by choosing the proper gain values of the controllers. Finally, the outputs of the PI controllers are added to the underlined decoupling terms of (5) to get the $d$-axis and the $q$-axis voltage references.

The $d$-axis current reference $i_{s d}^{*}$ is selected such that the stator-side inverter and the rotor-side inverter share the magnetizing currents equally as explained in (3). The $q$-axis current reference $i_{s q}^{*}$, which is equivalent to the torque command (6) when $\psi_{r}$ is constant, is obtained from the speed controller output. A simple PI controller is introduced for the speed control. The estimated rotor speed $\omega_{e}$ from (13) is used as a speed feedback for the PI controller.

\section{B. Rotor-Side Controller}

From the rotor-side voltage (4), it is seen that the rotor-side currents do not have any fluctuations when rotor flux magnitude $\left(\psi_{r}\right)$ is kept constant. If the stator-side currents $\left(i_{s d}, i_{s q}\right)$ are controlled, the rotor-side currents $\left(i_{r d}, i_{r q}\right)$ are generated automatically conforming to (3). Thus, the rotor-side inverter voltage reference is generated just to keep $\psi_{r}$ constant at its rated value at all rotor supply frequencies. A simple $V / f$ type
PWM controller serves this purpose easily. At any particular rotor speed $\left(\omega_{e}\right)$, the constant $V / f$-type PWM controller directly controls the rotor flux angular velocity $\left(\omega_{r}\right)$ with respect to the rotor. The stator supply frequency $\left(\omega_{s}\right)$, which is equal to the rotor flux speed $\left(\omega_{m r}\right)$ with respect to the stator, has a unique value as in (13).

\section{Frequency Command Generation for Rotor-Side Controller}

From (13) it can be seen that, for any particular rotor speed $\left(\omega_{e}\right)$, there are infinite possible combinations of stator supply frequency $\left(\omega_{s}\right)$ and the rotor supply frequency $\left(\omega_{r}\right)$. As mentioned earlier, the rotor supply frequency varies directly in open loop. The direct rotor supply frequency command $\left(\omega_{r}^{*}\right)$ is chosen in such a way that the rotor and stator supply frequencies never fall below $12 \mathrm{~Hz}$ at any rotor speed $\left(\omega_{e}\right)$. At very low rotor flux frequencies, it is very difficult to maintain the rotor flux $\psi_{r}$ constant by simply keeping the $V / f$ ratio constant. This happens since the rotor supply voltage becomes very small at these low frequencies. Similarly, at very low stator frequencies, the stator resistance drop becomes comparable to the stator supply voltage. Then, the estimation of stator flux using (9) also fails due to the variations as well as the inaccurate estimation of stator resistance drop. Thus, all sensorless control strategies, which depend on integration of the voltage to compute the flux vector, do not operate satisfactorily near zero supply frequency.

Based on these criteria, a proposed rotor supply frequency command $\left(\omega_{r}^{*}\right)$ profile is presented in Fig. 4. For rotor speeds above $35 \mathrm{~Hz}$, the rotor supply frequency can be calculated as

$$
\omega_{r}^{*}=-\frac{\omega_{e}}{2} .
$$

Below $30 \mathrm{~Hz}$, the magnitude of rotor supply frequency is either kept constant at $47 \mathrm{~Hz}$ or generated from the following equation:

$$
\omega_{r}^{*}=2 \pi \times 47-\omega_{e} .
$$




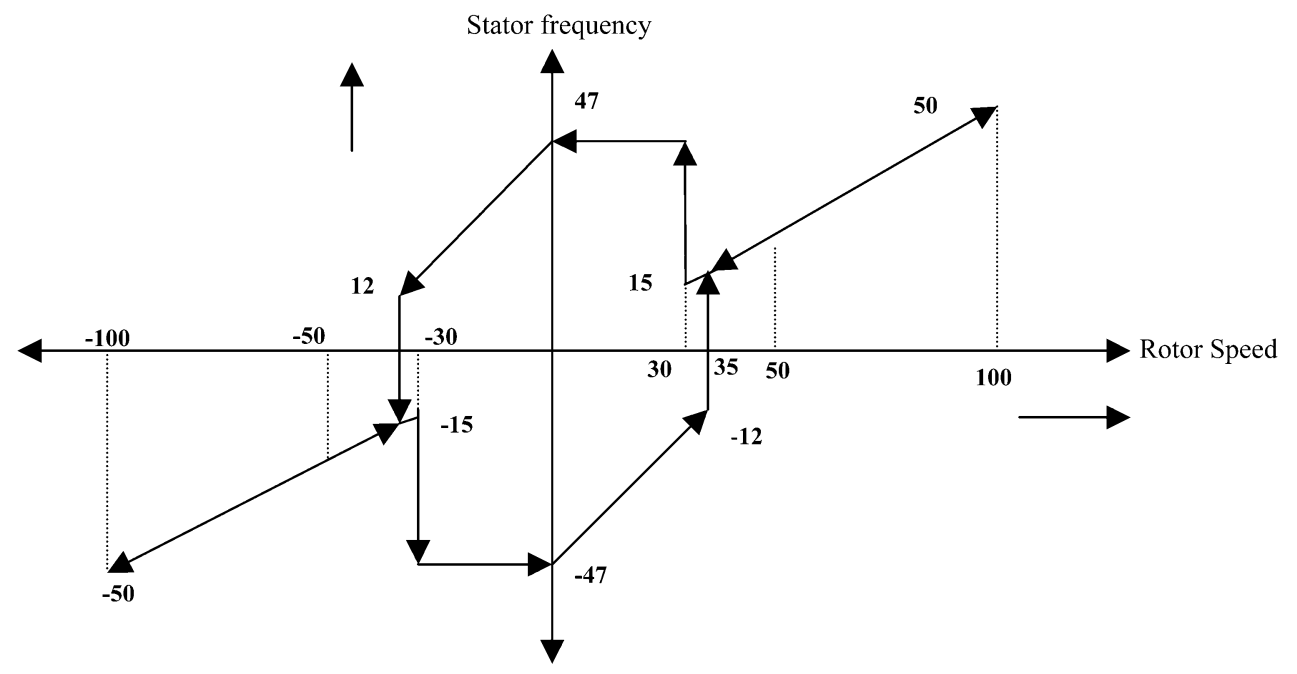

Fig. 5. Stator frequency versus rotor speed.

Now, from (13), it can be seen that the stator supply frequency is automatically generated around $47 \mathrm{~Hz}$ throughout the low-speed operation. This ensures a very reliable sensorless low-speed operation of the drive (including zero speed). At other rotor speeds, the supply frequencies on either side of the motor are always above $12 \mathrm{~Hz}$. Hence, the inaccurate estimations as well as the variations of stator and rotor resistance do not affect the motor performance, unlike the control strategies for standard sensorless drives. Fig. 5 shows the corresponding supply frequency generated on the stator side.

These frequency profiles are interchangeable. The given stator frequency plot can be used as a rotor frequency command. Then, the generated stator frequency plot will be the present rotor frequency command.

\section{Power Flow From Stator and Rotor}

There are two definite operating regions of this double-inverter-fed wound-rotor drive. One is for operation at rotor speeds below $30 \mathrm{~Hz}$ and the other is for operation at rotor speeds above $35 \mathrm{~Hz}$ (Figs. 4 and 5). For rotor speeds more than $35 \mathrm{~Hz}$, the rotor flux frequency and the stator flux frequency have equal magnitude, but opposite sign. Under this condition, the power flow from the stator and the rotor can be analyzed as follows.

Let us assume that the power fed from the stator-side inverter to the motor is $P_{s}$. The power fed from the rotor-side inverter to the motor is $P_{r}$ and the output electrical power from the motor is $P_{e}$. For any arbitrary steady motor torque $m_{d}, P_{s}$, and $P_{r}$ can be written as

$$
\begin{aligned}
& P_{s}=m_{d} \omega_{s} \\
& P_{r}=\left(-m_{d}\right) \omega_{r} .
\end{aligned}
$$

Now, from (14), it is seen that for

$$
\omega_{s}=-\omega_{r}=\frac{\omega_{e}}{2}
$$

the sign of $P_{s}$ and $P_{r}$ are the same, i.e., during motoring operation of the motor, both the stator inverter and the rotor inverter feed the power to the motor. On the other hand, during regeneration, both inverters draw power from the motor and feed it to the common dc bus. This is called supersynchronous operation of the motor.

Now, each inverter rated for 1 p.u. is capable of producing rated torque $\left(m_{\text {rated }}\right)$ at rated frequency $\left(\omega_{\text {rated }}\right)$. When these inverters operate at a condition confirming to (17), the net output power from the motor is

$$
P_{e}=P_{s}+P_{r}=2 \omega_{\text {rated }} m_{\text {rated }} .
$$

Thus, the motor output power becomes twice the rated power. This is a very attractive advantage of this drive for high-power applications. At this condition, the rotor speed $\left(\omega_{e}\right)$ becomes twice the rated speed (17).

For rotor speeds below $30 \mathrm{~Hz}$, the rotor supply frequency $\left(\omega_{r}\right)$ and the stator flux frequency $\left(\omega_{s}\right)$ have the same sign. However, their magnitudes are different. For any positive torque $m_{d}$, one inverter feeds power to the motor in excess of the required output power from the motor (16). The inverter on the other side draws this excess power from the motor and feeds it to the common dc bus (16). The balance power is equal to the net output power from the motor $\left(P_{e}\right)$

$$
P_{e}=m_{d}\left(\omega_{s}-\omega_{r}\right)
$$

Therefore, there is a circulation of power from the stator to the rotor through the motor. This is called subsynchronous operation of the motor.

\section{EXPERIMENTAL RESULTS}

The experimental verification is carried out on a 50-hp wound-rotor induction motor. Both the stator and the rotor are fed with three-phase insulated gate bipolar transistor (IGBT) inverters. The switching frequency of the inverters is $2.2 \mathrm{kHz}$. A common dc bus supplies power to both the inverters. A digital controller carries out the control of the inverters. This digital control board (Fig. 14) is based on a 16-bit fixed-point digital signal processor (DSP). There are two current sensors to measure the stator-side line currents and another set of two line current sensors for the rotor-side line currents. There is a voltage sensor to measure the dc-bus voltage. The control software for the drive is written in assembly language. The 


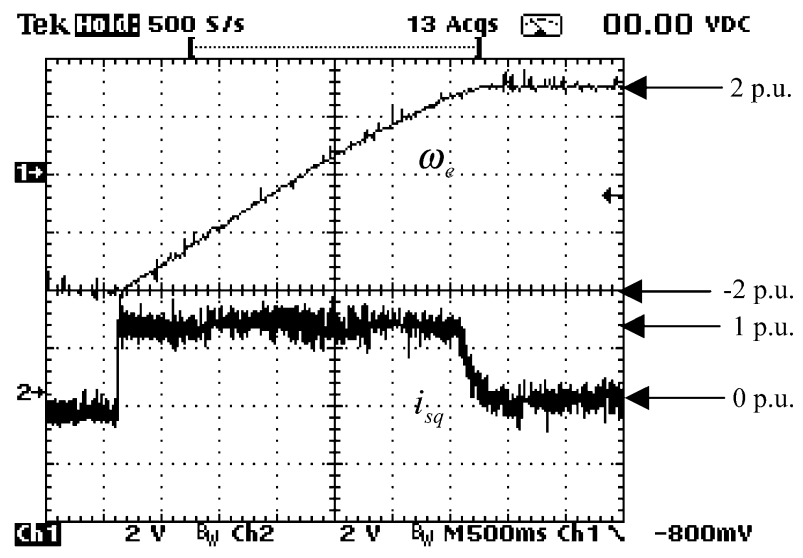

Fig. 6. Rotor speed and torque current for sudden 2-p.u. speed reversal at no load.

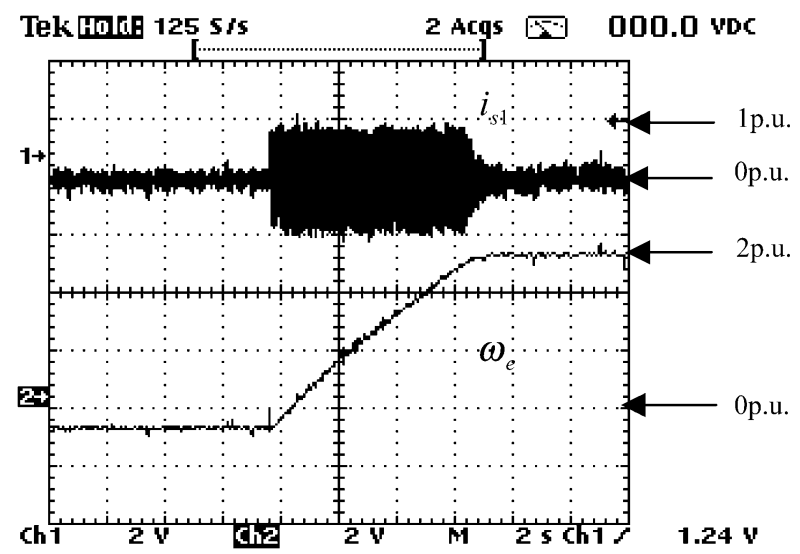

Fig. 7. Experimental waveform of stator current for sudden change in rotor speed.

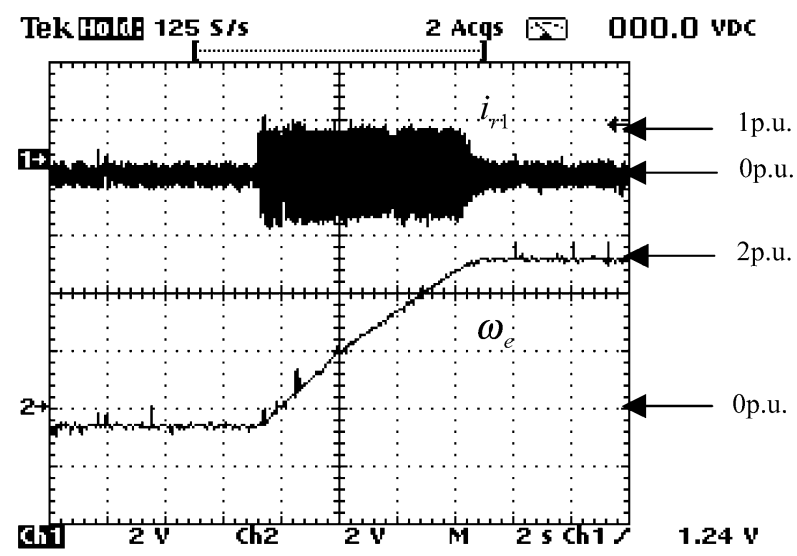

Fig. 8. Experimental waveform of rotor current for sudden change in rotor speed.

control cycle time is set at $100 \mu \mathrm{s}$. The experimental waveforms are shown in Figs. 6-13.

\section{A. Steady-State and Dynamic Performance}

Fig. 6 shows the waveforms of actual speed and the torque current when sudden 2-p.u. speed reversal is performed at no load. It is important to note that 1-p.u. torque is maintained from -2- to 2-p.u. rotor speed. This confirms the capability of the

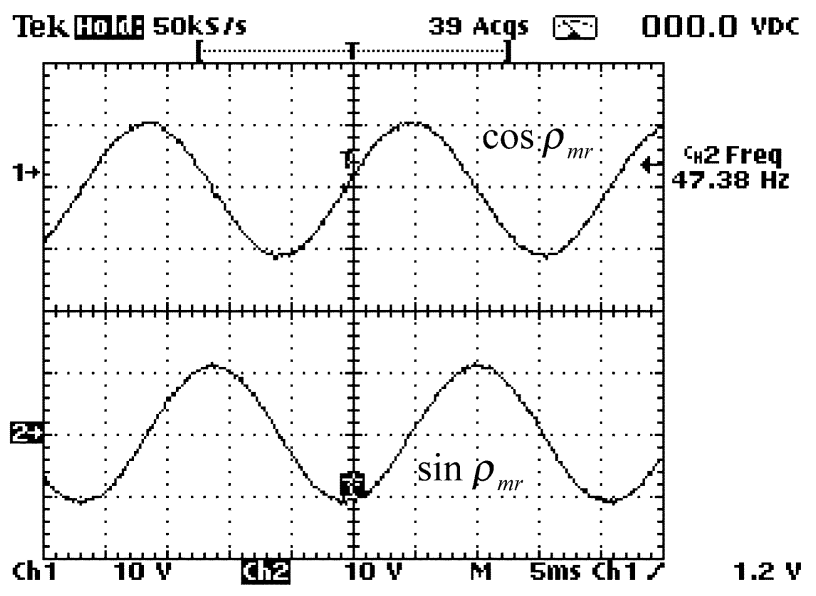

Fig. 9. Experimentally generated unit vectors for rotor-flux orientation.

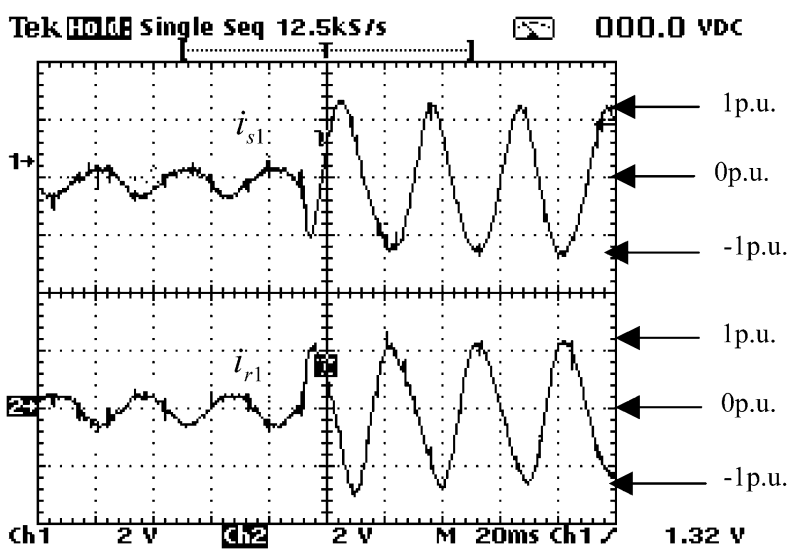

Fig. 10. Stator and rotor currents for sudden change in load at supersynchronous speed.

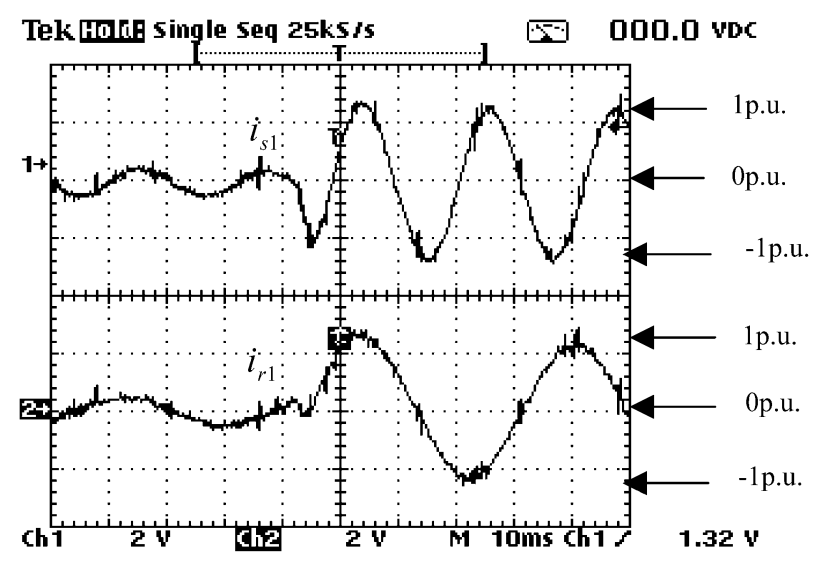

Fig. 11. Stator and rotor currents for sudden change in load at subsynchronous speed.

drive to extract 2-p.u. power from a 1-p.u. motor without electrically overloading the machine. Figs. 7 and 8 show the stator and the rotor current waveforms during speed ramp up to 2-p.u. rotor speed. The steady 1-p.u. current during this transient operation ensures the good current control at all operating rotor speeds. Fig. 9 shows the estimation of the rotor-flux vector position at zero rotor speed. Figs. 10 and 11 show the motor currents during 


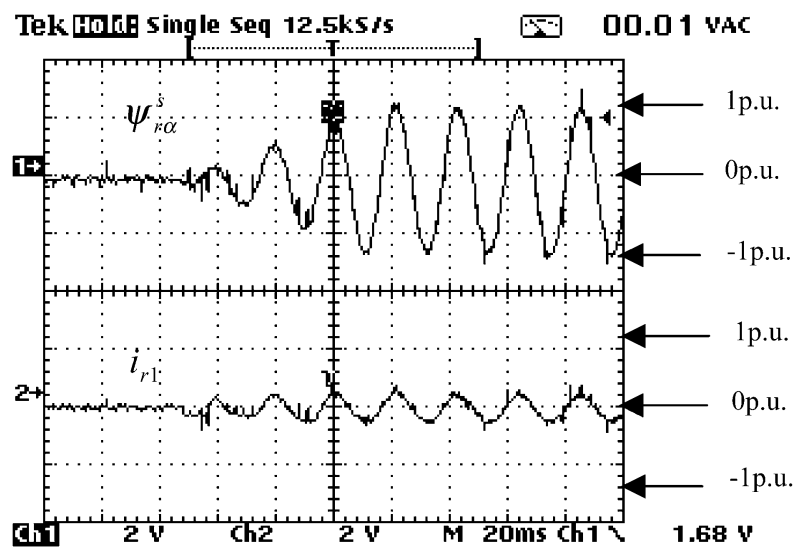

Fig. 12. Experimental waveform of rotor flux and current at START with $\varepsilon=$ $180^{\circ}$.

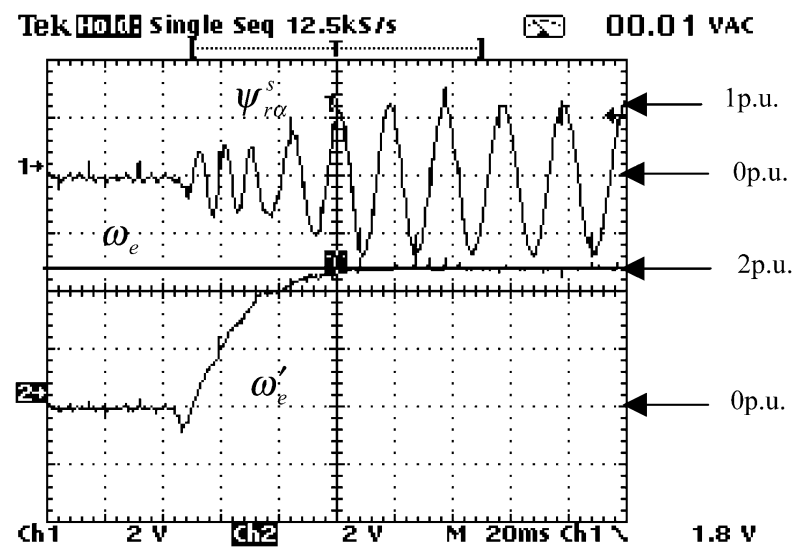

Fig. 13. Estimated rotor speed and rotor flux at START with 2-p.u. actual rotor speed.

sudden loading at subsynchronous and supersynchronous operation of the motor.

\section{B. Starting Performance}

Figs. 12 and 13 show the starting performance of this sensorless drive under two critical conditions. The rotor position $(\varepsilon)$ at starting is not available to the controller. However, the proposed algorithm estimates the rotor-flux position correctly from the beginning since no initial value of rotor-flux position is assumed at the start. This is justified in Fig. 12 where the motor is started when the rotor axis makes an angle of $180^{\circ}$ with the stator axis at the start. Smooth starting current ensures the proper orientation at starting without any rotor position sensor. Naturally, this allows the drive to start on-the-fly. Fig. 13 shows the on-the-fly start when the motor is running at 2-p.u. speed. Fig. 14 is a photograph of the DSP-based digital control board.

\section{CONCLUSION}

A new sensorless vector control strategy has been proposed here for a double-inverter-fed wound-rotor induction motor. Current control is done on one side of the wound-rotor induction motor. Direct frequency control is applied on the other side

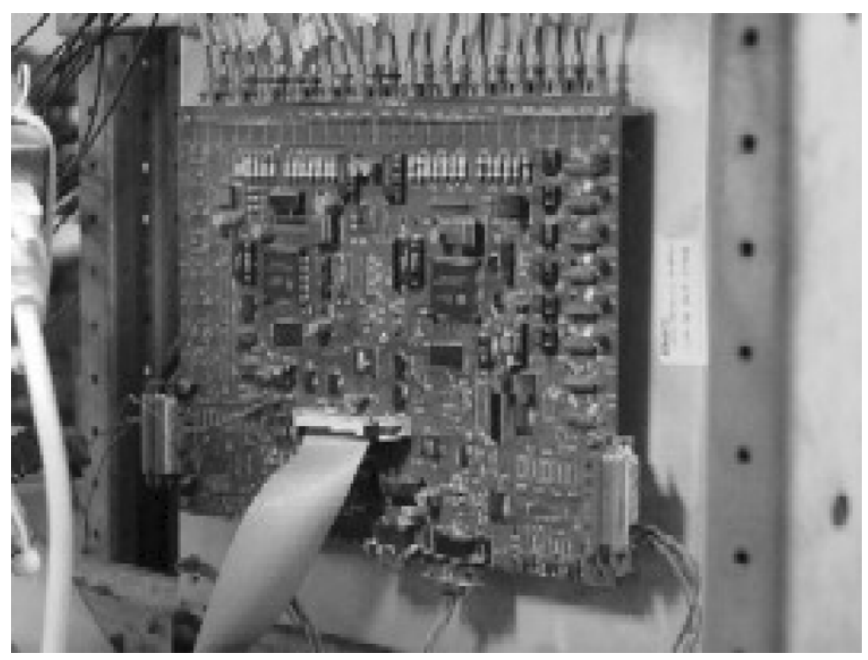

Fig. 14. DSP-based digital control board.

of the same motor. The resulting control is rugged and reliable. With the introduction of this controller, the double-inverter-fed wound-rotor induction motor runs up to twice the rated speed in either direction, without field-weakening operation. This, in turn, ensures full-torque operation for the motor up to twice the rated speed and, hence, double the rated power can be extracted from the motor. Because of good current control on one side of the motor, there are no current transients in the motor even during fast changes in torque or speed. The frequency profiles, proposed here, ensure that the frequency on either side of the doubly fed wound-rotor induction motor never goes below $12 \mathrm{~Hz}$. Because of this feature, this control scheme is not affected by variations in motor parameters like stator and rotor resistance. Therefore, the performance of the drive improves considerably. This feature also ensures that high torque can be obtained without any thermal stress on any of the inverter legs for any rotor speed. The proposed controller estimates the rotor speed from the motor model and performs the control operation. Thus, it eliminates the need for a costly, unreliable position transducer and makes the drive more rugged. This sensorless method is very reliable even at zero rotor speed because of the rotor frequency profile proposed in this paper. This sensorless drive is capable of starting on-the-fly.

\section{APPENDIX \\ MOTOR PARAMETERS}

The parameters of the tested motor are as follows:

rated power: $50 \mathrm{hp}$;

rated frequency: $50 \mathrm{~Hz}$;

rated speed: $1475 \mathrm{r} / \mathrm{min}$;

stator voltage: $400 \mathrm{~V}$;

rotor voltage: $325 \mathrm{~V}$;

rated current: $63.7 \mathrm{~A}$;

$R_{s}=0.137 \Omega$;

$R_{r}=0.1 \Omega$;

$L_{0}=40.1 \mathrm{mH}$;

$\sigma_{s}=0.033$;

$\sigma_{r}=0.022$. 


\section{REFERENCES}

[1] R. Datta, "Rotor side control of grid-connected wound rotor induction motor and its application to wind power generation," $\mathrm{Ph} . \mathrm{D}$. dissertation, Dept. Elect. Eng., Indian Inst. Sci., Bangalore, India, 2000.

[2] Y. Kawabata, E. Ejiogu, and T. Kawabata, "Vector-Controlled doubleinverter-fed wound-rotor induction motor suitable for high-power drives," IEEE Trans. Ind. Applicat., vol. 35, pp. 1058-1066, Sept./Oct. 1999.

[3] I. Takahashi and T. Noguchi, "A new quick-response and high-efficiency control strategy of an induction motor," IEEE Trans. Ind. Applicat., vol. IA-22, pp. 820-827, Sept./Oct. 1986.

[4] T. G. Habetler and D. M. Divan, "Control strategies for direct torque control using discrete pulse modulation," IEEE Trans. Ind. Applicat., vol. 27, pp. 893-901, Sept./Oct. 1991.

[5] P. Tiitinen, "The next generation motor control method, DTC, direct torque control,' in Proc. PEDES'96, New Delhi, India, 1996, pp. $37-43$.

[6] K. D. Hurst, T. G. Habetler, G. Griva, and F. Profumo, "Zero-Speed tacholess IM torque control: Simply a matter of stator voltage integration," IEEE Trans. Ind. Applicat., vol. 34, pp. 790-795, July/Aug. 1998.

[7] T. Ohtani, N. Takada, and K. Tanaka, "Vector control of induction motor without shaft encoder," IEEE Trans. Ind. Applicat., vol. 28, pp. 157-164, Jan./Feb. 1992.

[8] K. Rajashekara, A. Kawamura, and K. Matsuse, Eds., Sensorless Control of AC Motor Drives. New York: IEEE Press, 1996.

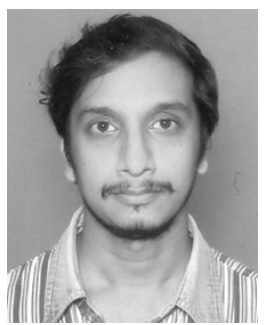

Gautam Poddar received the B.E. degree from Bengal Engineering College, Calcutta University, Calcutta, India, in 1992, the M.Tech. degree from the Indian Institute of Technology, Kharagpur, India, in 1994, and the Ph.D. degree from the Indian Institute of Science, Bangalore, India, in 2002, all in electrical engineering.

From 1995 to 2004, he was with the Power Electronics Group of the Electronics Research and Development Centre of India, where he was working in the field of power electronics and drives. In 2004, he joined the Department of Electrical Engineering, Indian Institute of Technology, Kharagpur, India, as an Assistant Professor. His fields of interest are control of high-power drives, sensorless control of ac motors, and active power filters.

Dr. Poddar was the recipient of an Indian National Academy of Engineers (INAE) Young Engineer Award in 2003.

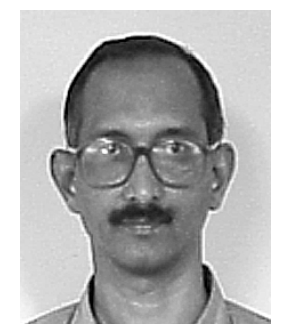

V. T. Ranganathan (M'86-SM'92) received the B.E. and M.E. degrees in electrical engineering from the Indian Institute of Science, Bangalore, India, and the Ph.D. degree from Concordia University, Montreal, QC, Canada.

In 1984, he joined the Electrical Engineering Department, Indian Institute of Science, where he is currently a Professor. His research interests are in the area of power electronics and motor drives. He has published several papers in the areas of vector control of ac drives, PWM techniques, split-phase induction motor drives, and slip-ring induction motor control. He is also a Consultant to industry in the above areas and has participated in a number of projects.

Prof. Ranganathan was the recipient of the Prize Paper Award of the Static Power Converter Committee of the IEEE Industry Applications Society, Tata Rao Prize of the Institution of Engineers, India, CV Raman Young Scientist Award, VASVIK Award, and Bimal Bose Award. He is a Fellow of the Indian National Academy of Engineering and Institution of Engineers, India. 